\title{
The Researches about Strength of Gas Production Casing Threads Connection
}

\author{
Hua Tong, Xiao-Hong Tang \\ Mechanical and Electrical Engineering, Southwest Petroleum University, Chengdu, Sichuan, China
}

\begin{abstract}
At present, the commonly used API at oilfield round thread of casing, is prone to damage. The forms of damage include dislocation, perforation, deformation and stress corrosion, nipple leaks, tripping failure and so on. Wherein, the leakage of nipple and tripping failures in deep and ultra-deep wells are especially. This paper regarded abroad oilfield casing leaks literature as the theoretical, based on API casing, analyzed the gas wellbore data in detail, analyzed the strength of the connection of its production casing, and got the finite element analysis stress curves of shale gas well production casing under different conditions, to provides a theoretical reference for the gas well casing joint strength evaluation.
\end{abstract}

Keyword: gas well; API casing thread; Von Mises equivalent stress; the connection strength; security

\section{Introduction}

In some oil and gas fields, casing threads leak and tripping failures accounted $16.35 \%$ of casing damage, which is a very serious impact on the oil and gas production, and caused huge economic losses. So study on strength of the threads connection is imminent. From the sealing mechanism, the different structures of the threads have different strength, Figure 1. Trapezoidal and round threads are the most commonly used. Round thread is easily processed, low-cost, while number of long round thread's connection screw more than short round thread, which make long round thread can bear more axial tension than short round. Long and short round thread tooth have the same basic design. Angle of thread of round thread is $60^{\circ}$, and the number of teeth per unit length is 8 teeth/in. Trapezoidal thread connection can bear more axial tension than the long round thread. Trapezoidal thread is square, and the number of teeth per unit length is 5 teeth/in.

The difference between straight connected thread and round thread, as well as trapezoidal thread, is that straight thread has no coupling, and its casing is integrally connected. With special straight thread connection casing is called no coupling casing. Ends of the tube have thick wall in order to meet the requirements of processing. No coupling casing's characteristic is that its pipe around threads connection has an smaller outer diameter than coupling casing, so that it is commonly used in annular clearance condition in order to cementing operations and running casing. However, it, with more thick tube, needs high-precision machining requirement. So no coupling casing is more expensive than round thread casing and trapezoidal threaded.

At present, the commonly used API casing at oilfield, round thread, is prone to damage. Wherein, the leakage of casing joints and tripping failures in deep and ultra-deep wells are particularly prominent part. Conventional completion strings apply threaded connections. Practice shows that the reliability of the production casing string is directly controlled by the reliability of the connected site. According to statistics, about $80 \%$ failures of the production casing have occurred in the casing joints. Compared to oil and water, threads sealing for gas needs a higher requirements.
Its connection strength is one of the most important indicators of the quality of the casing. So study on the casing thread connection strength is very important.

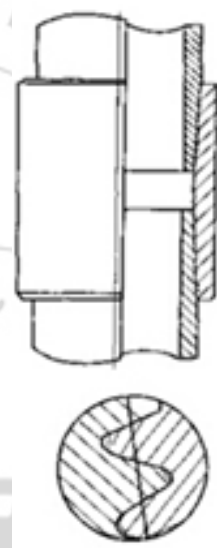

(a)
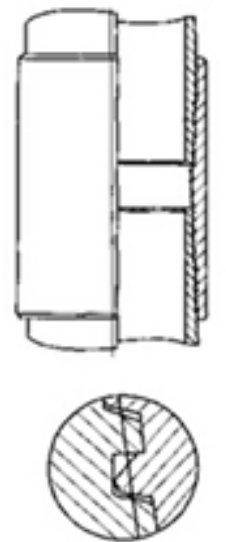
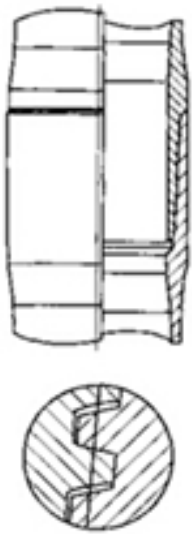

(a) Round thread (b) Trapezoidal thread

(c) Straight connection thread

Figure 1: API thread connection diagram

\section{Main Research Content}

Based on the domestic and international oilfield casing slip and spill literature surveys and statistical analysis, this paper selects API production casing thread as the research object, analyzes and evaluate the strength of the connection. Specific works are as follows.

(1) Using a large collection of home and abroad oil and gas casing literature, make some investigations and analyses of casing, and provide a reference for subsequent evaluation of the strength of the connection casing.

(2) Build casing thread finite element analysis model, 5 1/2 " Specifications. According to the mechanical model, analysis and evaluate the casing load distribution under axial tension, internal and external pressure, bending moment alone.

(3) Select four different load conditions as horizontal section and inclined section, vertical section, the maximum curvature to analysis its Von Mises equivalent stress distribution and provide a basis for evaluation of the strength of the connection thread. Horizontal section contains internal and external pressure; inclined section 


\section{International Journal of Science and Research (IJSR) \\ ISSN (Online): 2319-7064}

Index Copernicus Value (2013): 6.14 | Impact Factor (2015): 6.391

contains axial tension, internal and external pressure; vertical segment contains the axial tensile force, internal pressure, the maximum curvature contains axial tension, external pressure, and bending moment.

(4) Analysis the equivalent stress of the above casing and coupling model to provide a basis for evaluating the strength of the threaded connection.

(5) Draw conclusions, and give recommendations.

\section{Mining Conditions}

This gas-well design depth is $3820 \mathrm{~m}$, the actual drilled depth is $3800 \mathrm{~m}$, the average of two open caliper is $324.31 \mathrm{~mm}$, the average hole enlargement rate is $4.21 \%$, three open wells average diameter is $213.11 \mathrm{~mm}$. Part the well into three sections - horizontal section and inclined section, vertical section. Make analysis the load of each section, including preload, axial tension, internal and external pressure, bending moment.

\section{Finite Element Model of Threads}

The thread model is established based on basic dimensions of API round. Steel grade of casing is P110, wall thickness is $12.34 \mathrm{~mm}$. Elastic modulus, $E$, is $2.1 \mathrm{X} 105 \mathrm{MPa}$, Poisson's ratio is 0.3 , the yield strength is $758 \mathrm{MPa}$, the tensile strength is $862 \mathrm{MPa}$, the outer diameter of coupling is $153.7 \mathrm{~mm}$, the friction coefficient is 0.02 .

The lead angle of casing threads is small and thread load distribution is almost unaffected by that. Simplify the lead angle. Taking it into account that after ignoring the lead angle, the torque cannot be simulated. Here use interference fit to simulate the initial make-up torque. Make the casing and coupling into overall when establish model. The upper end of coupling set the fixed constraint. Use the C3D8R hexahedral - tetrahedral mixing unit meshing methods, as the Figure 2.
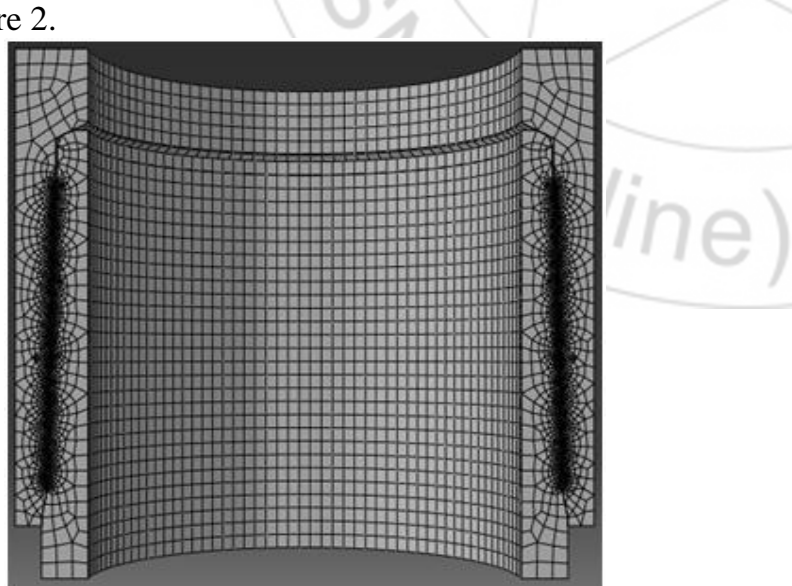

stress in material mechanics. It can be used to determine the strength of the connection, which was expressed as:

$\sigma=\sqrt{\sigma_{1}^{2}+\sigma_{2}^{2}+\sigma_{3}^{2}-\sigma_{1} \sigma_{2}-\sigma_{1} \sigma_{3}-\sigma_{2} \sigma_{3}}$

When $\sigma>\sigma_{s}$, Casing plastic deformation occurs. This section will establish finite element contact model of casing and coupling, and apply a single load (axial tension /KN: select 50, 250, 1250, 2000 respectively; internal pressure /MPa: select 25, 50, 75, 100; external pressure /MPa: select 25, 50, 75, 100; moment: select wellbore curvature $5^{\circ} / 30 \mathrm{~m}$, $\left.15 \% 30 \mathrm{~m}, 25 \% 30 \mathrm{~m}, 35^{\circ} / 30 \mathrm{~m}\right)$, obtained the connecting thread load distribution under a single load.

Through comparative analysis, provide a reference for the evaluation of the bonding strength when casings are under composite conditions. Before make an assessment, in order to facilitate the description, we will number the thread of casing and coupling. Numbers sequences are from end of the thread to the thread root, successively taking $1,2,3 \ldots$ 26 (threaded engagement of teeth). Select the maximum load as the load of the screw thread.

Observe the simulation of the stress cloud, red area is the area of maximum stress, when the casing joint only withstand axial tension, the maximum equivalent stress area centered on two roots threads of casing and coupling, and the rest the thread load distribution are more uniform and much smaller than the maximum value. Under the axial tensile force, casing and coupling load distribution is symmetrical, and the maximum stress on the first lap of casing roots threads, the minimum stress occurs at the outer wall of the coupling.

Figure 3 is expressed as a load distribution of each turn of the thread. From the load distribution curve, with the number of threads increased, the stress of threads from the big become small, then middle smooth, and become big at the ends, and reaches its maximum. It is a similar "basin-shaped" curve, and with the tensile stress increasing the maximum and the minimum stress both increases. When axial tension is $1250 \mathrm{kN}$, the casing does not reach the yield limit (equivalent stress is $543 \mathrm{MPa}$ ), and the material is elastically deformed, in normal working condition; When axial tension increases, so that the maximum equivalent stress reaches $758 \mathrm{MPa}$, the material will happen plastically deformation, with tension continuing to increase, the plastic deformation area becomes large; when the tension reaches $2000 \mathrm{kN}$, the maximum stress of casing threaded joint reaches $908 \mathrm{MPa}$, exceed the material yield limit, material damage, thread trip occurs. When axial tension exceeds the yield limit, the load distribution on the thread is not uniform any more. The reason of causing this phenomenon is the different size of the thread deformed plastically deformed material, and the shape becomes irregular, field operations must avoid such situations.

\section{Analysis of Simulation Results}

Von Mises stress is the fourth strength theory of equivalent 

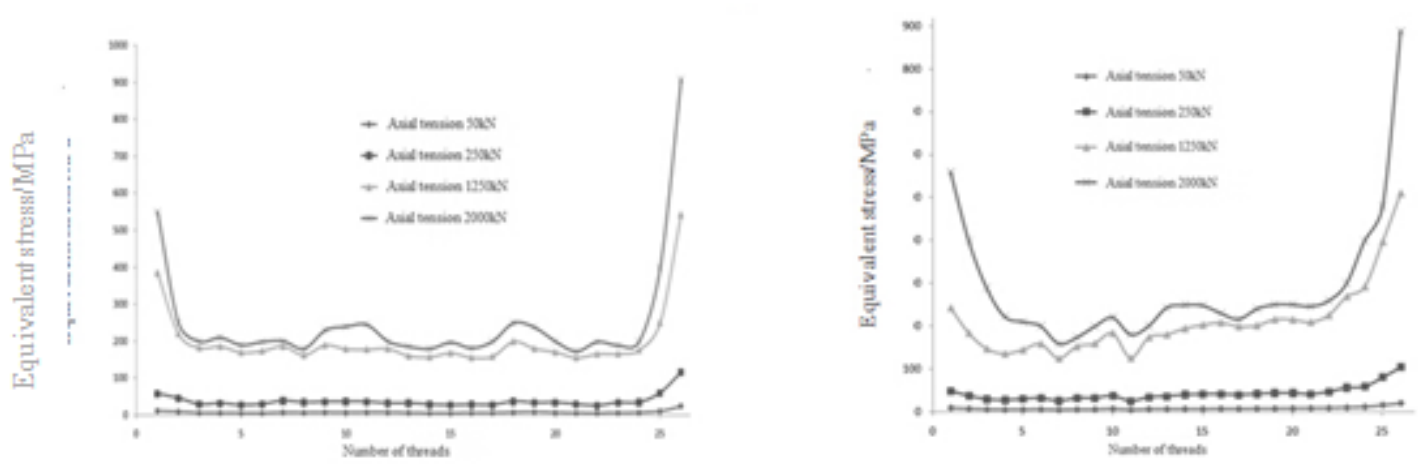

Figure 3(a): Casing thread tooth stress distribution Figure 3(b): Coupling thread tooth stress distribution

Figure 3: Casing and coupling thread tooth stress distribution under axial tension
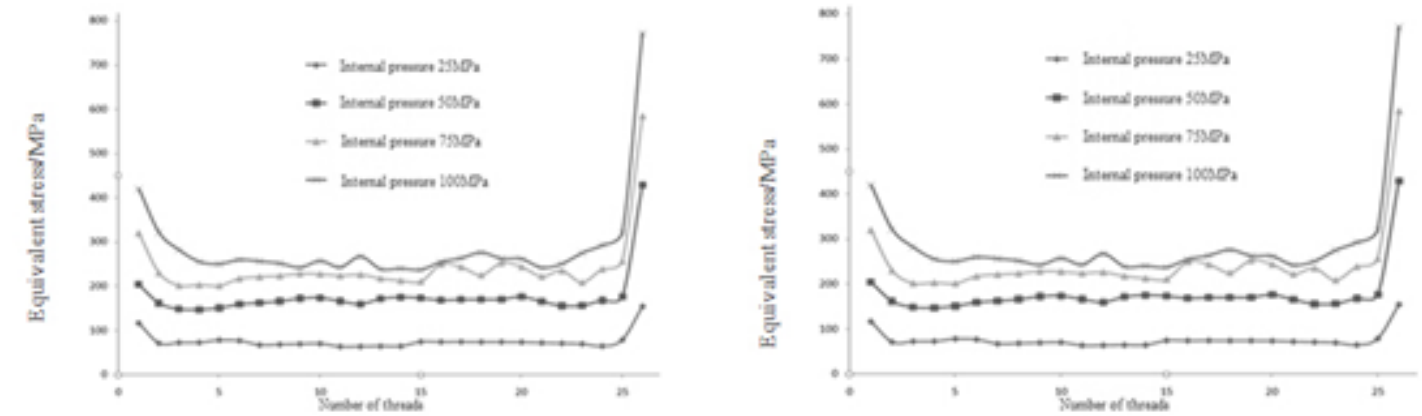

Figure 4(a): Casing thread tooth stress distribution Figure 4 (b): Coupling thread tooth stress distribution

Figure 4: Casing and coupling thread tooth stress distribution under internal pressure

Compared with Figure 3(a) and Figure 3(b), it shows that almost every thread load at casing is bigger than thread load at coupling on the same number. This explains why the casing withstands more load than coupling, which is also the main reason why the wall thickness of the casing is thicker than the coupling. Under the action of the internal pressure, here exists stress concentration on end of casing and coupling threads. When casing is under internal pressure, tube arise balloon. And the displacement in the axial of casing is limited, resulting bulging strain will be transformed into axial tension attached to the tubular body, which makes the load distribution under internal pressure similar to the load distribution under axial tensile force, "basin-like distribution", as Figure 4.

We can see not only the thread, but also the tubular body of casing, those load density was more significantly than coupling, which illustrates that under the internal pressure casing has a greater effect than coupling. The maximum equivalent stress occurs in the inner wall of the thread near the root of casing. When the internal pressure is less than $100 \mathrm{MPa}$, the stress of threaded joint subjected to will not exceed the material yield limit. When the internal pressure is too large, the casing will swell rupture, rupture location is most likely to occur in the vicinity of the casing thread root.

Figure 4(a) and Figure 4(b) is expressed as thread load distribution of casing and coupling under the action of the internal pressure. The gap between the curves show: when the internal pressure is small, the load on the thread rapidly increase with the internal pressure increases. When the internal pressure reaches $50 \mathrm{MPa}$, the thread load slowly increased with the internal pressure increases. However, the internal pressure loads on the casing thread roots and coupling is still just as great.

Under the Moment, load distribution throughout the casing is clearly not a symmetrical. Moment affects on the threaded joint is slightly different from the previous model. Model of casing previously mentioned takes $130 \mathrm{~mm}$, this model take the casing length $1000 \mathrm{~mm}$ in order to avoid situations that casing is so short to occur enormous error. Select the $\mathrm{x}$-direction as moment direction.

Bending moment has great effect on the connection strength of casing joint: When the borehole curvature was $5^{\circ} / 30 \mathrm{~m}(\alpha$ $=0.0029$ ), the maximum stress at the threaded joint reached $100 \mathrm{MPa}$; when the hole curvature was $35^{\circ} / 30 \mathrm{~m}$, the maximum stress at the threaded joint reached up to $1250 \mathrm{MPa}$, exceed the material yield limit a lot. But some of the load area is small, which make the loads circumferential distribution extreme non-uniform, and greatly reduced the connection strength of the threaded joint. So choose the right borehole curvature on the site. If curvature is too small, well trajectory cannot reach the target well deep. If curvature is too big, will lead casing damaged because of insufficient of connection strength.

Under the Moment, with the borehole curvature increases, the corresponding load of threads increased. The greater the curvature of the wellbore is, the faster loads increasing is. When the borehole curvature by $5 \% / 30 \mathrm{~m}$ increase to $15^{\circ} / 30 \mathrm{~m}$, the maximum load increased by $264 \mathrm{MPa}$. When the borehole curvature by $15 \% / 30 \mathrm{~m}$ increase to $25 \% / 30 \mathrm{~m}$, the maximum load increased by $393 \mathrm{MPa}$. When the borehole curvature reaches $25 \% / 30 \mathrm{~m}$, the material will yield. So the casing should not be set down into the well with borehole curvature reaching or exceeding $25^{\circ} / 30 \mathrm{~m}$. The maximum

\section{Volume 5 Issue 5, May 2016}




\section{International Journal of Science and Research (IJSR) \\ ISSN (Online): 2319-7064 \\ Index Copernicus Value (2013): 6.14 | Impact Factor (2015): 6.391}

load emerges at the last lap of the casing thread. Study on the last lap threads of casing, the load distribution shown in Figure 5. This figure sets the $\mathrm{x}$ direction as $0^{\circ}$. From $0^{\circ}$ along with clockwise direction to $360^{\circ}$, represent the last lap position of the thread. The length of center to the curve indicates the size of this position's stress. As it can be seen from Figure 5:

One side of casing threads bear tension, while others bear pressure. The pressed side area is slightly smaller than the pulled side. The loads of interface between tension and compression are much smaller than the same relative ring. The rest of the thread load distribution of the lap is substantially similar, and its corresponding load is smaller, not repeat them here.

\section{Conclusion}

(1) Finite element analysis is able to replace a lot of experimental simulation of complex mechanical model, and its result is reliable with low price. The established model should be considered the load boundary, meshing, size of calculation.

(2) This model is established based on API casing thread basic dimensions. The steel grade of casing is P110, the wall thickness is $12.34 \mathrm{~mm}$, the elastic modulus, $E$, is $2.1 \mathrm{X} 105 \mathrm{MPa}$, the Poisson's ratio is 0.3 , the yield strength is $758 \mathrm{MPa}$, the tensile strength is $862 \mathrm{MPa}$, the outer diameter of coupling is $153.7 \mathrm{~mm}$, the friction coefficient is 0.02 .

(3) Casing has a little lead angle, which is almost unaffected on load distribution of casing threads. Simplify it, and apply interference fit to simulate torque.

4) This paper analyzes the equivalent stress when casing is alone under the axial tension, internal and external pressures, bending moment, provided a reference for the evaluation of the connection strength of casing.

\section{References}

[1] Chen P. Drilling and completion engineering [M].Beijing: Petroleum Industry Press, 2005. (in Chinese)

[2] Kang X L. Sealing structure of the oil casing connected threads [J]. Field Equipment, 1997, 20 (1): 47-50.

[3] Yang L, Lin K, Han Y, et al. Casing characteristics in deep and ultra deep well [J].Oil Drilling \& Production Technology, 2003, 25 (2): 32-35.( in Chinese)

[4] Yang M H, Xia H N. Casing string design and strength check of HPHT well [J].Oil Drilling Technology, 2002 (30): 26-27. (in Chinese)

[5] Yang Z C, Li B. Sealing characteristics and stress analysis of Special casing joint [J]. Oil Field Equipment, 2004, 33 (5): 53-57. (in Chinese)

[6] Zhu X H, Dong L L, Tong $\mathrm{H}$, et al. Mechanical behavior short round API casing thread under tension complex loading [J]. Acta Petrolei Sinica, 2013, 34 (1): 158 - 163. (in Chinese)

[7] Zhuang Z. ABAQUS finite element example [M]. Science Press, 2005. (in Chinese) 